\title{
The Role of TNF $\alpha$ in the Periaqueductal Gray During Naloxone-Precipitated Morphine Withdrawal in Rats
}

\author{
Shuanglin Hao*,1,2,3, Shue Liu ${ }^{1,2,3}$, Xuexing Zheng ${ }^{1,2,3}$, Wenwen Zheng ${ }^{1,2,3}$, Handong Ouyang ${ }^{1,2}$, \\ Marina Mata ${ }^{1,2}$ and David J Fink ${ }^{1,2}$ \\ 'Department of Neurology, University of Michigan, Ann Arbor, MI, USA; ${ }^{2}$ Ann Arbor VA Healthcare System, Ann Arbor, MI, USA
}

\begin{abstract}
Tolerance and dependence are common complications of long-term treatment of pain with opioids, which substantially limit the long-term use of these drugs. The mechanisms underlying these phenomena are poorly understood. Studies have implicated the midbrain periaqueductal gray (PAG) in the pathogenesis of morphine withdrawal, and recent evidence suggests that proinflammatory cytokines in the PAG may play an important role in morphine withdrawal. Here we report that chronic morphine withdrawalinduced upregulation of glial fibrillary acidic protein (GFAP), tumor necrosis factor alpha (TNF $\alpha$ ) and phosphorylation of ERKI/2 (pERKI/2) in the caudal ventrolateral PAG (vIPAG). Microinjection of recombinant TNF $\alpha$ into the vIPAG followed by intraperitoneal naloxone resulted in morphine withdrawal-like behavioral signs, and upregulation of pERKI/2, expression of Fos, and phosphorylation of CAMP response element binding (PCREB) protein. We used a herpes simplex virus (HSV)-based vector expressing p55 soluble TNF receptor (sTNFR) microinjected into the PAG to examine the role of the proinflammatory cytokine TNF $\alpha$ in the PAG in the naloxone-precipitated withdrawal response. Microinjection of HSV vector expressing sTNFR into the PAG before the start of morphine treatment significantly reduced the naloxone-precipitated withdrawal behavioral response and downregulated the expression of GFAP and TNF $\alpha$ in astrocytes of the PAG. TNFR type I colocalized with neuronal pERKI/2. Microinjection of HSV vector expressing sTNFR into the PAG also significantly reduced the phosphorylation of both ERKI/2 and CREB, and reduced Fos immunoreactivity in neurons of the PAG following naloxone-precipitated withdrawal. These results support the concept that proinflammatory cytokines expressed in astrocytes in the PAG may play an important role in the pathogenesis of morphine withdrawal response.

Neuropsychopharmacology (20II) 36, 664-676; doi:I0.1038/npp.2010.197; published online 10 November 2010
\end{abstract}

Keywords: morphine withdrawal; PAG; TNF ; soluble TNF receptor; gene therapy

\section{INTRODUCTION}

Opiate addiction, a significant clinical and social problem, is complicated by the phenomena of tolerance and dependence (Koob and Le Moal, 1997). Dependence is characterized by the withdrawal reaction (physical dependence) and/or the presence of a 'drug-craving' component (psychological dependence) (Taylor and Fleming, 2001). The unpleasant withdrawal phenomena may occur when continuous administration of the opiate drug is stopped suddenly, or may be precipitated by the administration of an opioid antagonist to animals receiving opiate drugs

* Correspondence: Professor S Hao, Department of Anesthesiology, University of Miami Miller School of Medicine, 1550 NW I Oth Avenue, Fox Bldg 304C (R37I), Miami, FL 33I36, USA, Tel: + I 305243 6420, E-mail: shao@med.miami.edu

${ }^{3}$ Current address: Department of Anesthesiology, University of Miami Miller School of Medicine, Miami, FL, USA

Received 12 April 2010; revised 27 September 2010; accepted I October 2010
(Cami and Farre, 2003; Fishbain et al, 1992; Koob and Le Moal, 1997). Although psychological dependence is an important feature of dependence, physical dependence itself is a prominent cause of compulsive drug-taking behavior and short-term relapse (Kirby et al, 1990). Elucidation of the mechanisms involved in physical dependence is crucial to understanding addiction and developing more effective treatment strategies to attenuate or overcome opioid dependence.

Neuroanatomic sites implicated in physical dependence include the locus coeruleus, periaqueductal gray (PAG), and ventral tegmental area (Christie et al, 1997; Ledeboer et al, 2007b). A role for the PAG in the pathogenesis of opioid withdrawal signs has been suggested by functional and biochemical studies. Opioid antagonists microinjected into the PAG elicit strong withdrawal signs in rats implanted with pellets of morphine (Laschka et al, 1976; Maldonado et al, 1992), and intraperitoneal injection of naloxone precipitates morphine withdrawal in rats receiving a chronic infusion of morphine into the PAG (Bozarth, 1994). 
Recent evidence has implicated a glial 'inflammatory' response in the pathogenesis of opioid tolerance and dependence. Astrocytes and microglia respond to repeated opioid administration in a proinflammatory manner, with upregulation of markers of activation and expression of proinflammatory cytokines. Chronic morphine tolerance is accompanied by glial activation in the spinal cord, posterior cingulate cortex, and hippocampus; co-administration of morphine with a spinal glial activation inhibitor results in a maintenance of analgesic efficacy and a corresponding reduction of glial activation (Song and Zhao, 2001). Chronic administration of systemic or intrathecal morphine activates spinal glia cells with downstream upregulation of proinflammatory cytokines (Johnston et al, 2004; Raghavendra et al, 2002). Drugs that suppress glial proinflammatory responses can suppress the expression of morphine withdrawal (Hutchinson et al, 2009). For example, AV411 (glial inhibitor) suppresses the production of proinflammatory cytokines and chemokines, nitric oxide, phosphodiesterase activity, and reactive oxygen species (Hutchinson et al, 2009), and AV411 treatment significantly decreases spontaneous opioid withdrawal and reduces the increases in microglial and astrocytic activation in morphine withdrawal (Hutchinson et al, 2009). However, the anatomic site at which glial activation is important in the phenomenon of withdrawal has not been established.

Gene transfer offers the possibility to produce and release bioactive macromolecules in a local site in vivo. Among the several gene transfer vectors that are available, herpes simplex virus (HSV) is particularly well suited for delivery of gene in the nervous system (Fink et al, 1996). In the central nervous system, HSV vectors encoding $B c l-2$ and GDNF gene microinjected into rat substantia nigra result in a doubling in cell survival and a $50 \%$ increase in tyrosine hydroxylase immunoreactive neurons in the substantia nigra (Natsume et al, 2001). In this study, we investigated the role of tumor necrosis factor alpha (TNF $\alpha$ ) in the PAG and the effect of HSV-mediated expression of p55 soluble TNF receptor (sTNFR) into the ventrolateral PAG (vlPAG) on naloxone-precipitated morphine withdrawal in rats. We found that vector-mediated STNFR expression attenuated the intensity of naloxone-induced morphine withdrawal in rats.

\section{METHODS}

\section{Construction of Herpes Simplex Virus Vector Expressing the p55 sTNFR}

The vector TOTNFSR contains the coding sequence for amino acids 1-211 of the human p55 sTNFR under regulatory control of the HSV ICPO immediate-early (IE) promoter in the UL41 locus of an HSV recombinant defective for HSV genes ICP4, ICP22, and ICP27. T0TNFSR was generated as described previously (Hao et al, 2007; Peng et al, 2006). Control vector TOZ is identical to TOTNFSR, except that it contains the E. coli lacZ gene in place of $p 55$ sTNFR. To determine the efficiency of transgene expression, we constructed an HSV vector containing the enhanced green-fluorescent protein (EGFP) gene.
Animal Protocol and Evaluation of Morphine

\section{Physical Dependence}

Male Sprague-Dawley rats (body weight 225-250 g) were housed one to two per cage approximately 1 week before the beginning of the study, with free access to food and water and maintained on a $12: 12$, light: dark schedule at $21^{\circ} \mathrm{C}$ and $60 \%$ humidity. All housing conditions and experimental procedures were approved by the University of Michigan IACUC.

Morphine dependence was induced using a dosage protocol modified from Trang et al (2003). Rats were given escalating doses of morphine for a period of 5 days as follows: day $1,10 \mathrm{mg} / \mathrm{kg}$ (0800 hours, i.p.) and $15 \mathrm{mg} / \mathrm{kg}$ (2000 hours); day 2, 15 and $20 \mathrm{mg} / \mathrm{kg}$; day 3, 25 and $30 \mathrm{mg} / \mathrm{kg}$; and day 4,35 and $40 \mathrm{mg} / \mathrm{kg}$. On day 5 , animals received a morning injection of $50 \mathrm{mg} / \mathrm{kg}$, and $1 \mathrm{~h}$ later, naloxone ( $4 \mathrm{mg} / \mathrm{kg}$, i.p.) was administered to produce morphine withdrawal. Immediately after naloxone administration, animals were placed individually in test chambers consisting of boxes $\left(50 \times 35 \times 45 \mathrm{~cm}^{3}\right)$ and withdrawal signs were evaluated over the course of $30 \mathrm{~min}$. Two types of signs were measured during abstinence, as described previously (Hao et al, 2009; Valverde et al, 2001). Episodes of wetdog shakes and jumps were counted (ie, recorded quantitatively); teeth chattering (vacuous chewing), diarrhea, rhinorrhea, ptosis, irritability, lacrimation, escaping, penile erection, and abnormal posture were evaluated over 5 -min periods, with one point being given for the presence of each sign during each period. The number of periods showing the sign was then counted (maximum score, 6). The body weight of the rats was recorded before the injection of naloxone and then again at $60 \mathrm{~min}$ after the naloxone injection. A global withdrawal score was calculated for each rat by assigning a weighting factor to the various physical signs of withdrawal (Gellert and Holtzman, 1978). Morphine injection and behavior counting were carried out by a blinded operator.

\section{PAG Cannula Implantation}

Rats were prepared for intracranial $\mathrm{TNF} \alpha$ administration by placing those anesthetized with chloral hydrate $(300 \mathrm{mg} / \mathrm{kg}$, i.p.) in a stereotaxic headholder. The skull was exposed, and stainless-steel guide cannula (26 gauge) was directed bilaterally toward the vlPAG (AP $-8.3 \mathrm{~mm}$ using bregma as $0, \mathrm{ML} \pm 0.6 \mathrm{~mm}, \mathrm{DV}-4.5 \mathrm{~mm}$ from the base of the dura). The guide cannula was cemented in place and secured to the skull by two small stainless-steel screws. A stainless-steel stylet was inserted after surgery and left in place until the time of intracranial injection (Hao et al, 2003a). At 10 days after implantation, $20 \mathrm{ng} \mathrm{TNF} \alpha$ was injected into the PAG through intracranial injector.

\section{Western Blot}

The brains were harvested under deep anesthesia. A tissue block including a segment at the level of the vlPAG (Hao et al, 2003a) was cut (Figure 1). The vlPAG from the tissue block will be harvested by taking punches with a 14-gauge puncture needle as described previously (Guo et al, 2007). The tissue punched was homogenized with $100 \mu$ l of ice-cold 




Figure I Caudal VIPAG, site of microinjection of the vectors and where GFAP, TNF $\alpha$, pERKI/2, Fos, and pCREB were assessed. Rectangles depict the region of the caudal vIPAG (stereotaxic coordinates bregma -7.8 to $-8.3 \mathrm{~mm}$ ).

lysis buffer ( $150 \mathrm{~mm}$ sodium chloride, $1.0 \%$ NP-40, $0.5 \%$ sodium deoxycholate, $0.1 \%$ SDS, $50 \mathrm{mM}$ Tris, $\mathrm{pH} 8.0$ ) containing protease inhibitors (Sigma, St Louis, MO) and phosphatase inhibitor cocktails 1 and 2 (Sigma). Tissue homogenates were sonicated and then centrifuged at $15000 \mathrm{~g}$ for $20 \mathrm{~min}$ at $4^{\circ} \mathrm{C}$. The supernatant was collected and assayed for protein content using the BCA assay method (Pierce, Rockford, IL) and stored at $-20{ }^{\circ} \mathrm{C}$ until further use. Total protein $(40 \mu \mathrm{g})$ was electrophoresed on a $10 \%$ SDS-PAGE gel, transferred to a PVDF membrane, and blocked with $5 \%$ non-fat dry milk. The primary antibodies (rabbit polyclonal anti-TNF $\alpha, 1: 500$, Chemicon, Temecula, CA; mouse anti-pERK1/2 (Thr202/Tyr204) monoclonal antibody, 1:1000, Cell Signaling Technology, Danvers, MA; rabbit anti-Fos polyclonal antibody, 1:500, Santa Cruz Biotechnology, Santa Cruz, CA; rabbit anti-phosphorylation of cAMP response element binding (pCREB) (ser133) (87G3) monoclonal antibody, 1:100, Cell Signaling Technology; mouse anti- $\beta$-actin, $1: 8000$, monoclonal antibody, Sigma) were incubated overnight at cold room in fresh blocking buffer. The membranes were incubated with complementary secondary antibodies $(1: 3000$, peroxidasecoupled or HRP-biotinylated IgG, Sigma) for $1 \mathrm{~h}$ at room temperature. The membranes were washed in washing buffer for another $30 \mathrm{~min}$, and the antibodies were then revealed using Super Signal west dura extended duration substrate (Thermo, Rockford, IL). For densitometric analyses, blots were quantified with the Quantity One analysis software (Bio-Rad, Hercules, CA). The membranes were stripped and re-probed with mouse anti- $\beta$-actin IgG (Sigma Aldrich, Saint Louis, MO) as a loading control. The results were expressed as the ratio to $\beta$-actin immunoreactivity.

\section{Microinjection of HSV Vectors into the vLPAG}

Rats were prepared for intracranial vector administration by placing those anesthetized with chloral hydrate anesthesia $(0.3 \mathrm{~g} / \mathrm{kg}$, i.p. $)$ in a stereotaxic headholder. The skull was exposed, and a stainless-steel guide cannula (26 gauge) was directed toward the vlPAG (AP $-8.3 \mathrm{~mm}$ using bregma as 0 , $\mathrm{ML} \pm 0.6 \mathrm{~mm}, \mathrm{DV}-5.5 \mathrm{~mm}$ from the base of the dura) (Hao et al, 2003a). The coordinates were obtained from the atlas of Paxinos and Watson (1986). Rats were randomly divided to receive a bilateral vlPAG injection of $2 \mu \mathrm{l}$ containing $10^{9} \mathrm{PFU}$ of sTNFR-expressing vector TOTNFSR or control vector $\mathrm{T} 0 \mathrm{Z}$ with micropump $(0.5 \mu \mathrm{l} / \mathrm{min})$. After microinjection, the injector was left in situ for an additional $1 \mathrm{~min}$ before it was removed.

\section{ELISA}

At 10 days after microinjection with vectors into the vlPAG, the brain was removed, frozen on dry ice, and stored at $-80^{\circ} \mathrm{C}$. A block of the PAG including a $1 \mathrm{~mm}$ segment at the level of the vlPAG was cut, turned coronally, and the vlPAG harvested by taking punches with a 14-gauge puncture needle as described previously (Guo et al, 2007). The tissue was minced and placed in ice-cold homogenization buffer containing protease inhibitor cocktail tablet (Roche, Mannheim, Germany) (Hao et al, 2003b) and the amount of human p55 sTNFR I was determined using an ELISA kit (R\&D Systems, Minneapolis, MN).

\section{Immunohistochemistry and Image Analysis}

Immunohistochemical expression of pERK1/2, Fos, and PCREB in the vlPAG in rats with morphine or saline was investigated as described previously (Chieng et al, 1995). At 10 days after microinjection of vectors, rats received chronic morphine or saline for 5 days. At day $5,1 \mathrm{~h}$ after last morphine or saline, naloxone was given to precipitate withdrawal syndrome. At $1 \mathrm{~h}$ after naloxone, the animals were perfused with $4 \%$ paraformaldehyde in $0.1 \mathrm{M}$ phosphate-buffered saline. The brain was postfixed, cryoprotected, and $25 \mu \mathrm{m}$ coronal cryosections of brainstem incubated overnight at $4^{\circ} \mathrm{C}$ with rabbit anti-pERK1/2 (Thr202/Tyr204) polyclonal antibody $(1: 300$, Santa Cruz Biotechnology), rabbit anti-Fos polyclonal antibody ( $1: 500$, Santa Cruz Biotechnology), and rabbit anti-pCREB (ser133) (87G3) monoclonal antibody (1:100, Cell Signaling Technology), followed by biotinylated goat anti-rabbit immunoglobulin G (Vector Laboratories, Burlingame, CA) and detected with diaminobenzidine (Elite $\mathrm{ABC}$ Kit, Vector Laboratories) as described previously (Hao et al, 2005; Hao et al, 2002). Sections from each animal were selected and the expression of Fos-LI, pERK1/2, or pCREB was evaluated 
by a blinded observer counting the number of immunopositive cells in the vlPAG.

For immunofluorescence detection, cryosections were probed overnight with goat anti-mouse glial fibrillary acidic protein (GFAP) monoclonal antibody (1:5000, Sigma) or rabbit anti-GFAP polyclonal antibody $(1: 2000$, DakoCytomation, Glostrup, Denmark), goat anti-rat TNF $\alpha$ antibody ( $1: 100$; R\&D systems, Minneapolis, MN), mouse anti-NeuN monoclonal antibody (A60) (1:5000, Millipore, Billerica, MA), goat anti-TNFRI polyclonal antibody (E20) $(1: 100$, Santa Cruz Biotechnology), rabbit anti-pERK1/2 (Thr202/ Tyr204) polyclonal antibody (1:300, Santa Cruz Biotechnology), rabbit anti-Fos polyclonal antibody (1:500, Santa Cruz Biotechnology), and rabbit anti-pCREB (ser133) (87G3) monoclonal antibody (1:100, Cell Signaling Technology), and then followed by incubation with complementary secondary antibodies labeled with blue-fluorescent Alexa Fluor 350, green-fluorescent Alexa Fluor 488, or redfluorescent Alexa Fluor 594 (1:2000, Molecular Probes, Eugene, OR) $2 \mathrm{~h}$ at room temperature and photographed using a fluorescence microscope.

For immunostaining analysis, sections were selected and scanned using a Nikon fluorescence microscope. Images were then captured with a CCD CoolSNAP EZ camera (Photometrics, Tucson, AZ), and image densities were analyzed with the NIS-Elements Basic Research software (Nikon). The percentage change of staining density in sham groups was calculated as $100 \%$.

\section{Drugs and Data Analysis}

Morphine hydrochloride was obtained from Elkins-Sinn (Cherry Hill, NJ). Naloxone hydrochloride was obtained from Sigma. Recombinant rat $\mathrm{TNF} \alpha$ was purchased from PeproTech. TNF $\alpha$ was administered into the vlPAG by a $30-$ gauge stainless-steel injection cannula, which extended $1.0 \mathrm{~mm}$ below the tip of the guide. The injection cannula was connected with polyethylene tubing (PE-10) filled with drug solution. A volume of $0.5 \mu \mathrm{l}$ was injected over $30 \mathrm{~s}$ by means of a Hamilton syringe. After administration, the injector was left in situ for an additional 1 min before it was removed and replaced by the guide stylet. Naloxone was injected intraperitoneally in a volume of $3 \mathrm{ml} / \mathrm{kg}$ of body weight. All drugs were dissolved in physiological $(0.9 \%)$ saline. The statistical significances of the differences were determined by ANOVA (StatViewJ 5.2) followed by post hoc comparisons using Fisher's PLSD test. $P$-values of less than 0.05 were considered to be statistically significant. The difference between the time-course curves of the withdrawal behavior was determined using General Linear Model, repeated measure with SPSS software.

\section{RESULTS}

\section{Expression of GFAP, TNF $\alpha$, and pERK1/2 induced by Morphine Withdrawal in the vLPAG}

Rats were treated with escalating doses of morphine or saline for 5 days. At $1 \mathrm{~h}$ after the last dose of morphine or saline, a withdrawal response was precipitated by naloxone. Morphine withdrawal signs were observed for $30 \mathrm{~min}$ after naloxone. At $1 \mathrm{~h}$ after naloxone, the brains were harvested
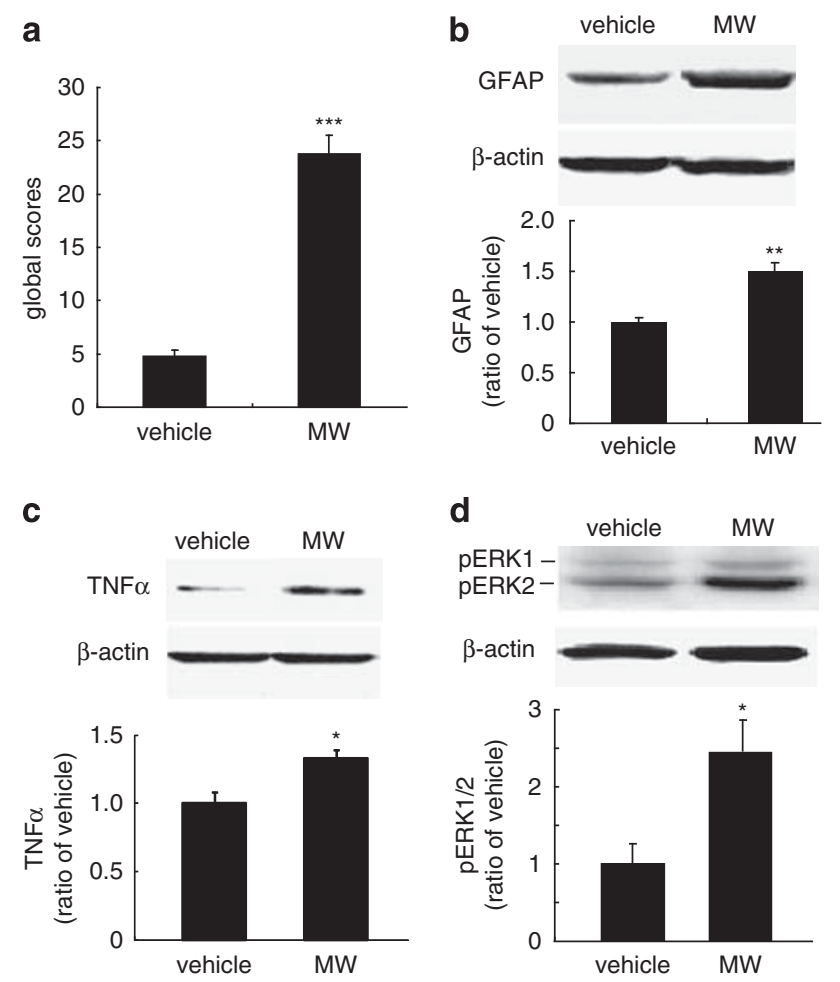

Figure 2 The behavioral syndrome and the expression of GFAP, TNF $\alpha$, and pERKI/2 in morphine withdrawal. Escalating doses of morphine (MW) or saline (vehicle) were administered for 5 days, followed by a single dose of naloxone to precipitate the withdrawal response. The global withdrawal scores were significantly higher in morphine-treated animals compared with the control group (a), **** $p<0.00$ I vs vehicle, $n=5-6$, t-test. Morphine withdrawal also induced significant upregulation of GFAP (b), TNF $\alpha$ (c), and $p-E R K I / 2$ (d), * $p<0.05$, ** $p<0.01$ vs vehicle, $n=4-6$, $t$-test.

under deep anesthesia and frozen at dry ice, and expression of GFAP, TNF $\alpha$, and pERK1/2 in the vlPAG determined by western blot. In rats treated with morphine, withdrawal signs began about 5 min after injection of naloxone. Rats treated with escalating morphine followed by naloxone exhibited signs of withdrawal (Figure 2a) as well as significant upregulation of GFAP (Figure 2b), TNF $\alpha$ (Figure 2c), and pERK1/2 (Figure 2d) in the vlPAG compared with the saline-treated control animals.

\section{The Effect of Exogenous TNF $\alpha$ Injected into the vLPAG}

In order to determine whether exogenous $\mathrm{TNF} \alpha$ would induce a withdrawal-like response, we microinjected recombinant $\mathrm{TNF} \alpha$ or saline into the caudal vlPAG, and $1 \mathrm{~h}$ later, injected the animals with naloxone $(4 \mathrm{mg} / \mathrm{kg}$, i.p.). $\mathrm{TNF} \alpha$, but not saline-injected animals, exhibited morphine withdrawal-like behaviors after naloxone (Figure 3a). TNF $\alpha$ microinjection also induced phosphorylation of ERK $1 / 2$ in the vlPAG (Figure 3b), upregulated expression of Fos protein (Figure 3c), and phosphorylation of CREB (Figure 3d). Taken together with the observation of an increase in $\mathrm{TNF} \alpha$ in the PAG in animals undergoing morphine withdrawal (Figure 2c), these results support the role of TNF $\alpha$ in the PAG in the withdrawal phenomenon. 

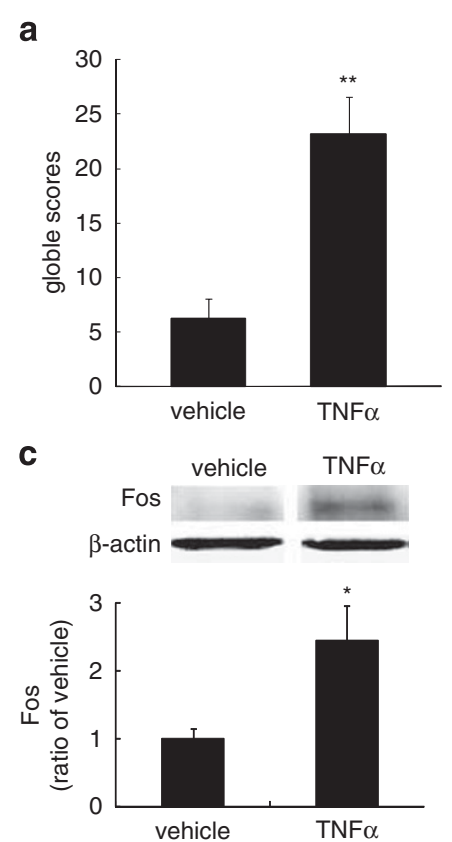

Figure 3 The effect of microinjection of TNF $\alpha$ into the caudal VIPAG. Recombinant TNF $\alpha(20 \mathrm{ng})$ or saline (vehicle) was microinjected into the VIPAG, followed I h later by intraperitoneal administration of naloxone $(4 \mathrm{mg} / \mathrm{kg}$, i.p.). The behavioral signs were observed for $30 \mathrm{~min}$ after naloxone. (a) The microinjection of TNF $\alpha$ into the caudal VIPAG-induced morphine withdrawal-like behavioral signs after naloxone. Single microinjection of recombinant TNF $\alpha$ into the VIPAG also evoked upregulation of pERKI/2 (b), expression of Fos (c), and phosphorylation of CREB (d) while naloxone was given. ${ }^{*} p<0.05$ vs vehicle, $* * * 0.0$ I vs vehicle, $n=5$, $t$-test.

\section{TOTNFSR Expresses TNFSR in the PAG}

To determine the cellular distribution of transgene expression after microinjection of the HSV vector into the PAG, we injected a vector encoding EGFP into the PAG. At 10 days after injection, robust expression of GFP was seen in cells of the PAG (Figures 4a-c). GFP expression colocalized with NeuN immunostaining, but not with GFAP immunostaining, indicating predominant expression in neurons, which was consistent with the previous report (Barrot $e$ t al, 2002). To assess expression of sTNFR, 10 days after microinjection of vector TOTNFSR expressing the p55 TNFR, the vlPAG was harvested and the amount of human sTNFR measured by ELISA. Microinjection of TOTNFSR, but not T0Z, significantly induced the expression of sTNFR in the vlPAG (Figure 4d).

\section{Microinjection of TOTNFSR into the PAG Blunts the Morphine Withdrawal Syndrome}

sTNFR I can neutralize the effect of TNF $\alpha$ binding to TNFR on the neurons. The results from studies above suggest the important role of $\mathrm{TNF} \alpha$ in morphine withdrawal. In this experiment, we challenged whether overexpression of TNFSR mediated by HSV vector reduced morphine withdrawal behavior signs and/or neurochemical changes. In sham animals, control vector TOZ was microinjected into the PAG and saline $(1 \mathrm{ml}$, twice a day, i.p.) was administered for 5 days. At $1 \mathrm{~h}$ after the last injection of
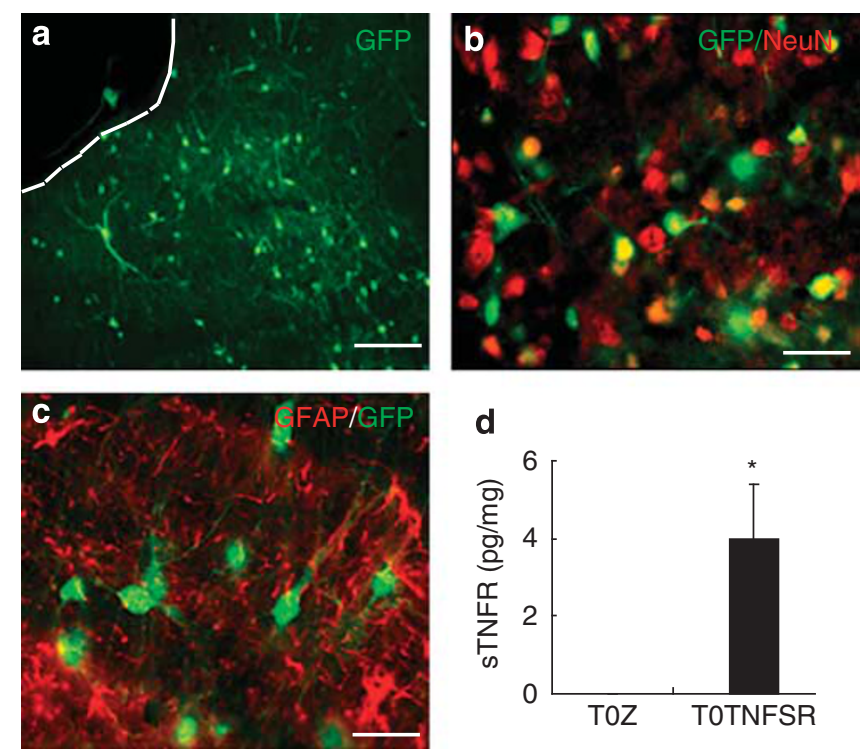

Figure 4 Localization of GFP after microinjection of an HSV vector encoding EGFP into the PAG. GFP expression (a) was colocalized with NeuN immunostaining (b), but not GFAP immunostaining (c). HSV vector mediated expression of $\mathrm{p} 55$ sTNFR, 10 days after vector injection into the PAG measured by ELISA. TOTNFSR microinjection significantly induced the expression of sTNFR in the PAG (d). ${ }^{*} p<0.05$ vs T0Z, $n=3-4$, ANOVA.

saline, animals received naloxone administration $(4 \mathrm{mg} / \mathrm{kg}$, i.p.). Rats microinjected with TOTNFSR, but not T0Z exhibited a significant decrease in teeth chattering, the number of jumps, and 'wet-dog' shakes (Figure 5). Although the score of ptosis, penile erection, rhinorrhea, irritability, and lacrimation in rats microinjected with TOTNFSR was less than that in rats with TOZ, these changes were not statistically significant (data not shown).

A global withdrawal score was individually calculated for each rat for the observed withdrawal signs (Gellert and Holtzman, 1978). One or two 'wet-dog' shakes or jumps contributed 2 points; three or more contributed 4 points. Teeth chattering, diarrhea, ptosis, penile erection, rhinorrhea, irritability, and lacrimation contributed 1 point in every $5 \mathrm{~min}$. The global withdrawal score in rats microinjected with TOTNFSR was significantly less than that in animals microinjected with T0Z (Figure 5e and f). However, weight loss in rat microinjected with TOTNFSR was not different from that seen in those animals microinjected with T0Z in morphine withdrawal rats (Figure $5 d$ ).

\section{TNFSR Released by the HSV Vector in the PAG Prevents Astrocytic Activation and Production of TNF $\alpha$ in the PAG Induced by Naloxone-Precipitated Withdrawal}

To study the effect of naloxone-precipitated morphine withdrawal on astrocytic activation, we determined the relative density of GFAP immunostaining in the vlPAG (Mao et al, 2002). Coronal brain sections containing the caudal vlPAG in each animal were selected and the expression of GFAP in the vlPAG was evaluated by calculating the relative density of GFAP immunostaining with NIS-Elements Basic Research software. Quantitative analysis revealed that naloxone-precipitated morphine withdrawal induced a significant elevation in immuno- 
a
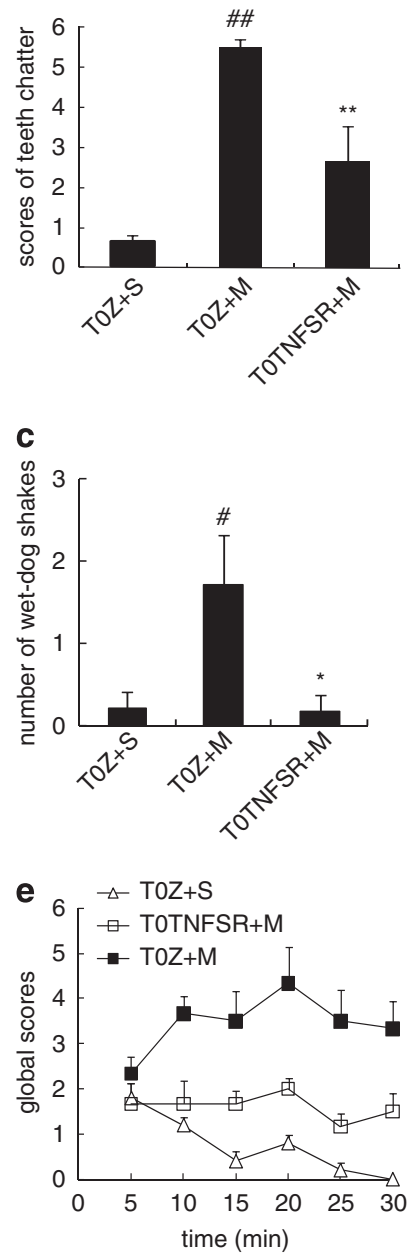

d

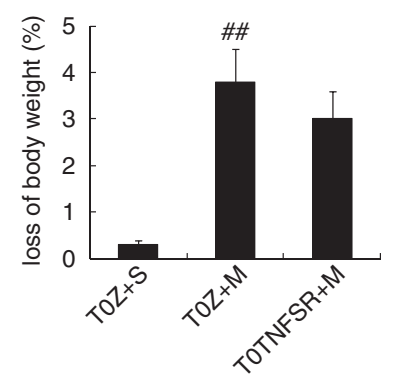

f

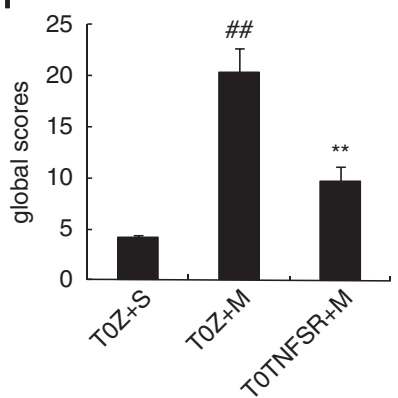

Figure 5 The effect of TOTNFSR or TOZ microinjected into the VIPAG on naloxone-precipitated morphine withdrawal. TOTNFSR injection significantly lowered the scores of teeth chattering (a), numbers of jumps (b), wet-dog shakes (c), and the global withdrawal score (f), but did not significantly reverse the loss of body weight (d), ${ }^{\#} p<0.05$, \#\# $p<0.0$ I vs $\mathrm{TOZ}+\mathrm{S}, * p<0.05, * * * 0.01$ vs TOZ $+M, n=6$, ANOVA. There was a significant difference between the curves of the time course of the global scores (e), $p<0.05$, SPSS, General Linear Model, repeated measure.

reactivity of GFAP compared with sham (Figure 6, left panel). Animals microinjected with TOTNFSR into the vlPAG showed a significant suppression of the increase in GFAP immunoreactivity in the vlPAG compared with animals microinjected with T0Z (Figure 6, left panel).

Astrocytes in the central nervous system are activated by chronic morphine and release proinflammatory cytokines. The expression of TNF $\alpha$ in the vlPAG was evaluated by calculating the relative density of TNF $\alpha$ immunostaining with NIS-Elements Basic Research software (Mao et al, 2002). Quantitative analysis revealed that naloxone-precipitated morphine withdrawal induced a significant elevation in immunoreactivity of TNF $\alpha$ compared with sham (Figure 6, right panel). TOTNFSR microinjected into the vlPAG in rats with naloxone-precipitated morphine withdrawal significantly suppressed the increase in the immunoreactivity of $\mathrm{TNF} \alpha$ in the vlPAG compared with T0Z (Figure 6, right panel).

GFAP


TNF $\alpha$
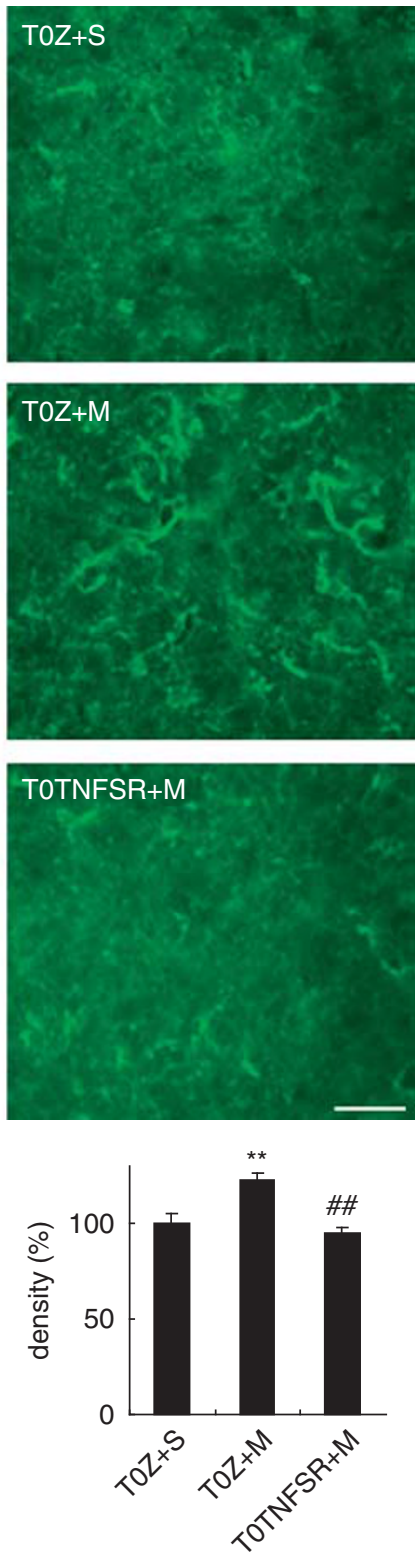

Figure 6 Quantification of the expression of GFAP and TNF $\alpha$ in the VIPAG in the morphine withdrawal. The expression of GFAP and TNF $\alpha$ in the VIPAG was evaluated by calculating the relative density of GFAP immunostaining with the NIS-Elements Basic Research software (Nikon). In sham group $(T O Z+S)$, animals received microinjection of TOZ into PAG and chronic saline (I ml, twice a day, i.p.) for 5 days; I h after last injection of saline, animals received naloxone $(4 \mathrm{mg} / \mathrm{kg}$, i.p.). The percentage of density from the sham group was calculated as 100\%. TOTNFSR (TNFSR + M), but not TOZ $(T O Z+M)$ injection, significantly suppressed the activation of GFAP in the PAG, ${ }^{*} * p<0.01$ vs sham, ${ }^{\# \#} p<0.01$ vs TOZ, $n=4-6$, ANOVA. TOTNFSR injection significantly suppressed the activation of TNF $\alpha$ in the PAG, ${ }^{* *} p<0.01$ vs sham, ${ }^{\#} p<0.01$ vs TOZ, $n=4-6$, ANOVA. Scale bar, $100 \mu \mathrm{m}$.

TNFSR released by HSV vector in the PAG reduces ERK 1/2 phosphorylation, blocks Fos expression, and decreases phosphorylation of CREB in rats with precipitated morphine withdrawal

Substantial evidence suggests that modulation of ERK phosphorylation in different regions of CNS may be 
relevant to tolerance, dependence, and reward (Cao et al, 2005; Valjent et al, 2004). Recent studies show that ERK activation increases in limbic areas of mice undergoing naloxone-precipitated morphine withdrawal (Hofford et al, 2009). Morphine withdrawal modulates gene expression in the nucleus tractus solitarius (NTS) through second-messenger signal-transduction systems including activation of ERK1/2 (Martin et al, 2009). An increase in pERK1/2 and phosphorylation of CREB in the NTS from mor- phine-withdrawn rats was reported (Martin et al, 2009). We investigated if naloxone-induced morphine withdrawal increased pERK1/2 in the PAG in rats. The number of pERK1/2 cells in rats with chronic morphine withdrawal was significantly higher than that in the sham group. TOTNFSR, but not TOZ, significantly decreased pERK1/2 cells in the vlPAG in morphine withdrawal rats (Figure 7, left panel).

Naloxone-precipitated morphine withdrawal induces the expression of the IE response gene Fos, a biomarker
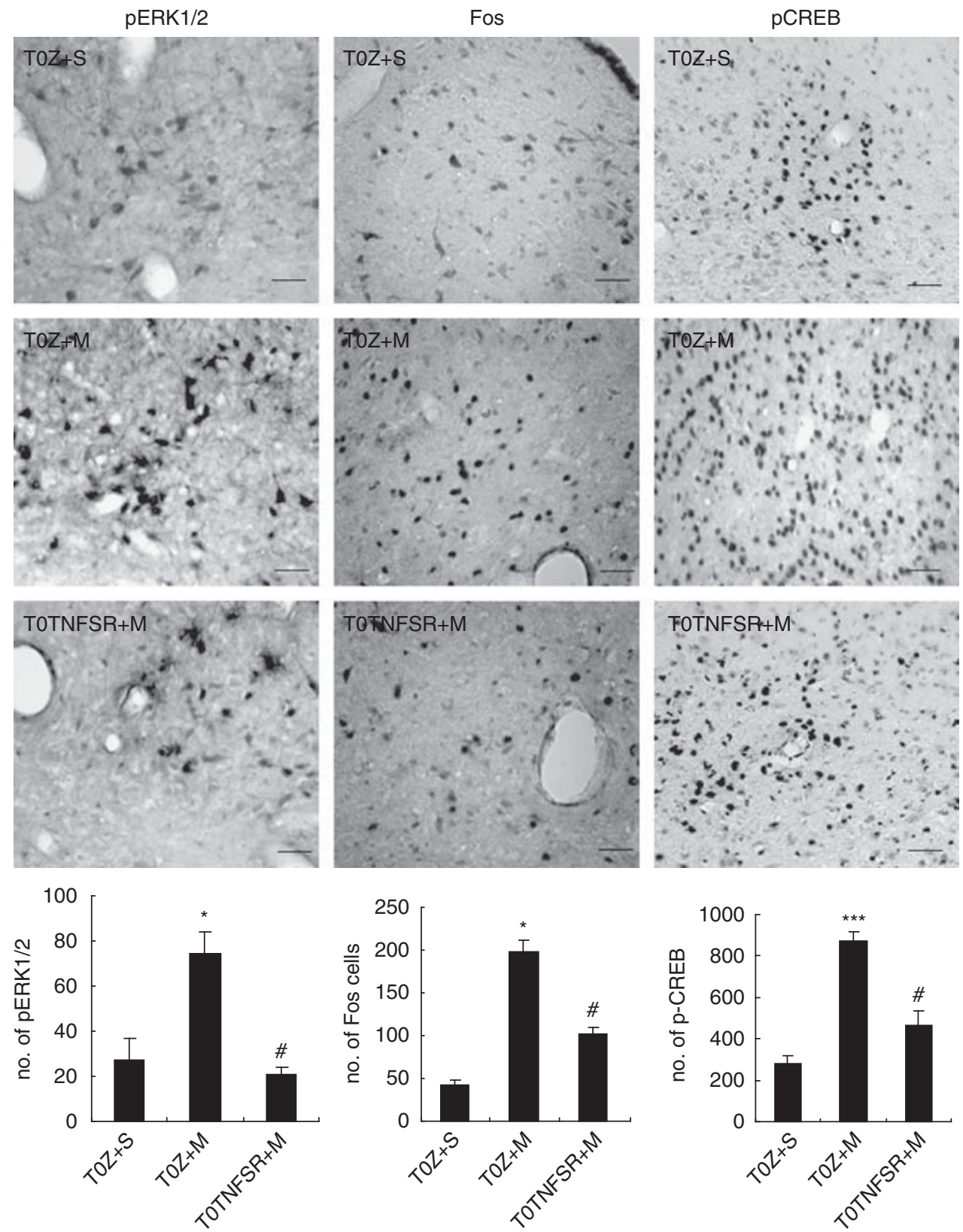

Figure 7 The effect of TOTNFSR or TOZ microinjected into the PAG on pERKI/2, Fos, and PCREB in the naloxone-precipitated morphine withdrawal. In sham group, animals received microinjection of TOZ into PAG and chronic saline (I ml, twice a day, i.p.) for 5 days; I h after last injection of saline, animals received naloxone administration ( $4 \mathrm{mg} / \mathrm{kg}$, i.p.). Morphine withdrawal induced a significant expression of pERKI/2, Fos, and $p C R E B$ in the vIPAG. In morphine withdrawal rats, TOTNFSR microinjection significantly suppressed expression of pERKI/2 in the vIPAG, ${ }^{*} p<0.05$ vs sham, ${ }^{\#} p<0.05$ vs T0Z, $n=4-6$, ANOVA. Scale bar, $100 \mu \mathrm{m}$. Morphine withdrawal induced a significant expression of Fos in the PAG. Animals microinjected with TOTNFSR significantly showed decrease in the amount of Fos immunostaining in the PAG, ${ }^{*} p<0.05$ vs sham, ${ }^{\#} p<0.05$ vs T0Z, $n=4-6$, ANOVA. Scale bar, I $00 \mu$ m. TOTNFSR microinjection significantly decreased the expression of the pCREB-positive cells in the vIPAG, $* * * * p<0.00$ I vs sham, ${ }^{p} p<0.05$ vs T0Z, $n=4-6$, ANOVA. Scale bar, $100 \mu \mathrm{m}$. 
of neuronal activity (Castilho et al, 2008; Chieng et al, 1995; McPhie and Barr, 2009). In this study, the expression of Fos was evaluated by counting the number of Fos immunopositive cells in the PAG. The number of Fos cells in rats with chronic morphine withdrawal was significantly higher than that in sham group. TOTNFSR microinjection significantly decreased Fos immunopositive cells compared with T0Z in the vlPAG in morphine withdrawal rats (Figure 7 , middle panel).

As CREB is known to mediate many of the effects of CAMP on gene expression, it has been suggested that CREB may be an important mediator of opiate-induced changes in gene expression that contribute to the state of opiate dependence (Nestler and Aghajanian, 1997). The expression of pCREB was evaluated by counting the number of immunopositive cells. The number of pCREB-positive cells in rats with chronic morphine microinjection was significantly higher than that in sham group. Microinjection of TOTNFSR, but not TOZ, significantly decreased the number of pCREB-positive cells in the vlPAG in morphine withdrawal rats (Figure 7, right panel).

\section{Determination of cellular localization of TNF $\alpha$,} endogenous TNFRI, pERK1/2, Fos, and pCREB in the vlPAG in naloxone-precipitation morphine withdrawal

To determine the cellular localization of TNF $\alpha$, TNFRI, pERK1/2, Fos, and pCREB, double- or triple-label immunostaining was carried out in vlPAG sections from animals injected with TOZ before morphine withdrawal. We found that almost all $\mathrm{TNF} \alpha$ immunostaining colocalized with GFAP but not NeuN, indicating that TNF $\alpha$ is expressed in astrocytes, but not neurons (Figure 8, upper panel). Immunostaining of pERK1/2 with GFAP and TNF $\alpha$ showed that $\mathrm{pERK} 1 / 2$ did not colocalize with either GFAP or TNF $\alpha$ immunostaining (Figure 8, middle panel). Double immunostaining showed that almost all $\mathrm{pERK} 1 / 2$ colocalized with NeuN, indicating that pERK1/2 is neuronal (data not shown). Triple-label immunostaining showed that pERK1/ 2 immunostaining was colocalized with both NeuN and TNFRI immunoreactivity (Figure 8, lower panel), indicating that $\mathrm{pERK} 1 / 2$ is expressed in TNFRI-expressed neurons. Double immunostaining showed that almost all pCREB or Fos staining was colocalized with NeuN, suggesting that both pCREB and Fos were neuronal (data not shown). We found that pERK1/2 immunostaining colocalized with Fos and pCREB (Figure 9).

\section{DISCUSSION}

There is growing evidence suggesting that glial activation plays a role in the phenomena of morphine tolerance and withdrawal (Hutchinson et al, 2009; Johnston et al, 2004; Raghavendra et al, 2002; Song and Zhao, 2001). The results of this study show that (1) morphine withdrawal induces astrocytic activation to release TNF $\alpha$ in the PAG; (2) exogenous $\mathrm{TNF} \alpha$ injection into PAG evokes morphine withdrawal-like behavior and upregulates expression of pERK1/2, Fos, and pCREB in the PAG; (3) morphine withdrawal results in the activation of neurons in the PAG characterized by phosphorylation of ERK1/2 and transcription factors of CREB and Fos; and (4) local overexpression of sTNFR by HSV vector in the PAG reverses astrocytes activation, decreases upregulation of $\mathrm{TNF} \alpha$ in astrocytes,


Figure 8 Determination of cellular localization of TNF $\alpha$, TNFRI, pERKI/2, Fos, and pCREB in the vIPAG. These rats were injected with control vector T0Z before the morphine withdrawal protocol. All labeled proteins are endogenous proteins. Triple-label immunostaining of GFAP, TNF $\alpha$, and NeuN in the VIPAG (upper panel). There was an almost complete colocalization between GFAP (blue) and TNF $\alpha$ (red) imaging, but TNF $\alpha$ did not colocalize with NeuN (green), which suggested that TNF $\alpha$ located on astrocytes, but not neurons. Immunostained pERKI/2 did not colocalize with either GFAP or TNF $\alpha$ (middle panel). Triple-label immunostaining (lower panel) showed that NeuN (blue) was colocalized with endogenous TNFRI (green). pERKI/2-positive cells (red) colocalized extensively with both NeuN and TNFRI immunostaining, suggesting that pERKI/2-positive cells be located on TNFRI-positive neurons. Arrows indicate double/triple-labeled cells. Scale bar, $100 \mu \mathrm{m}$. 

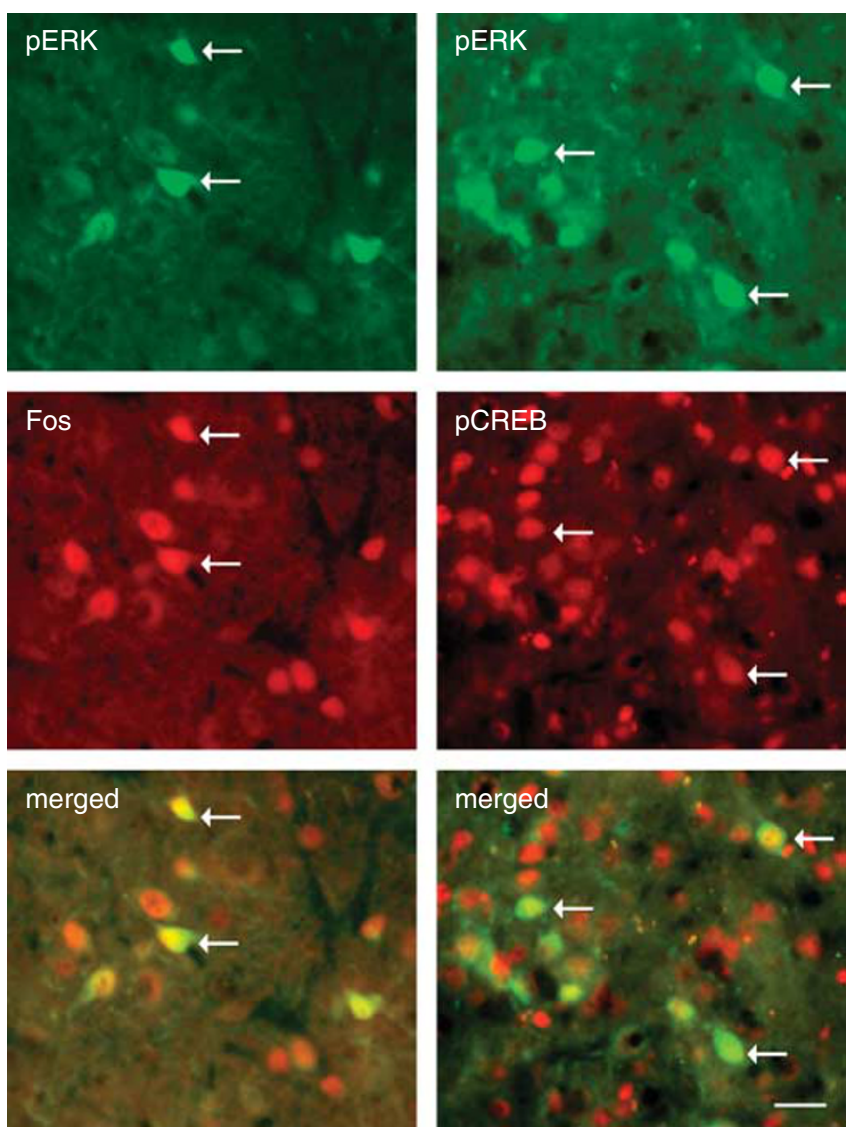

Figure 9 Colocalization of pERKI/2 and Fos (left panel) or pCREB (right panel). These rats were injected with control vector TOZ before the morphine withdrawal protocol. Double-label immunostaining showed that pERKI/2 was colocalized with either Fos or pCREB immunostaining. Arrows indicate double-labeled cells. Scale bar, $100 \mu \mathrm{m}$.

and reduces the expression of neuronal pERK1/2, pCREB, and Fos in the PAG in morphine withdrawal rats.

The PAG is rich in opioid receptors and endogenous opioid peptides, and mediates physiological functions, many of which are consistent with withdrawal behaviors (Bandler and Shipley, 1994). In addition, other brain regions implicated in opioid withdrawal, such as the nucleus accumbens and central nucleus of the amygdala, project heavily to the PAG (Harris and Aston-Jones, 1994; Stinus et al, 1990); major projections arising from the PAG innervate ventral and dorsal medullary regions of the brainstem that are implicated in the manifestations of opioid withdrawal (Williams et al, 2001). A role for the PAG in the expression of opioid withdrawal signs has been suggested by functional and biochemical studies. Opioid antagonists microinjected into the PAG elicit strong withdrawal signs in rats implanted with pellets of morphine (Laschka et al, 1976; Maldonado et al, 1992). Intraperitoneal injection of naloxone precipitates morphine withdrawal signs in rats with chronic morphine infused into the PAG (Bozarth, 1994). Endogenous peptide $\beta$-endorphin infused into the PAG for $72 \mathrm{~h}$ followed by naloxone elicits a typical morphine-like withdrawal syndrome (Wei and Loh, 1976). The number of Fos immunoreactive neurons in the lateral and ventrolateral subdivisions of the PAG is increased after opioid withdrawal in both awake and anesthetized rats, which is most predominant in the caudal areas of the vlPAG (Chieng et al, 1995; Couceyro and Douglass, 1995; Stornetta et al, 1993). Electrophysiologically, during opioid withdrawal opioid-sensitive neurons in the PAG display excessively enhanced activity caused by induction of a novel opioid-sensitive current distinct from the potassium conductance modulated by acute exposure to opioids (Chieng and Christie, 1996). Taken together, the data reviewed above suggest that the PAG plays a key role in the phenomena of morphine physical dependence.

Morphine dependence is characterized by somatic and motivational signs of withdrawal that likely contribute to the maintenance of opioid addictive behavior. Glia provide support and nutrition, maintain homeostasis, form myelin, and participate in signal transmission in the nervous system. Glial cells are activated in response to stimuli related to inflammation, ischemia, and invading pathogens. Morphine withdrawal induces glial activation and proinflammatory mediator expression in the different sites of the brain (Hutchinson et al, 2009). Chronic morphine treatment causes glial activation in the spinal cord, posterior cingulate cortex, and hippocampus; co-administration of morphine with a spinal glial activation inhibitor results in the maintenance of analgesic efficacy and a corresponding reduction of glial activation (Song and Zhao, 2001). Chronic administration of systemic or intrathecal morphine activates spinal glia cells with the upregulation of proinflammatory cytokines (Johnston et al, 2004; Raghavendra et al, 2002). The proinflammatory cytokines, in turn, oppose spinal morphine analgesia (Shavit et al, 2005). Antiinflammatory cytokines block the chronic morphine withdrawal-induced pain at the spinal level (Hutchinson et al, 2007; Raghavendra et al, 2002; Raghavendra et al, 2004). This evidence raises the question of whether glia activity may be involved in other chronic morphine-induced phenomena in the brain. Watkins and co-workers have shown that co-administration of morphine with systemic AV411 (glial inhibitor) suppresses morphine withdrawal precipitated by naloxone and that AV411 also suppresses systemic morphine-upregulated astrocytic and microglial activation markers in the brain and spinal cord (Ledeboer et al, 2007a; Lewis et al, 2006). In this study, we found that morphine withdrawal induces astrocytic activation to release $\mathrm{TNF} \alpha$ in the PAG and that exogenous $\mathrm{TNF} \alpha$ injection into PAG evokes morphine withdrawal-like behavior and upregulates the expression of pERK1/2, Fos, and pCREB in the PAG.

Glial cells, particularly astrocytes, envelop neuronal synapses and release gliotransmitters, which regulate synaptic transmission in those enveloped synapse (Bains and Oliet, 2007; Halassa et al, 2007). TNF $\alpha$ is one of a handful of identified gliotransmitters (Halassa et al, 2007; Volterra and Meldolesi, 2005). TNF $\alpha$ functions to modulate synaptic transmission (Bains and Oliet, 2007; Pickering et al, 2005). TNF $\alpha$ plays a central role in the glial-neuronal interactions that influence both neuropathic pain and drug abuse (Haydon et al, 2009; Schafers and Sommer, 2007). In immune cells, the membrane-anchored ligand has been shown to transduce 'reverse' signals into the ligandexpressed cell when activated by the cognate receptor(s) (Mata et al, 2008). By binding to TNF $\alpha$ and blocking its interaction with cell surface TNFRs, sTNFR reduces the 
biological effect of excess TNF $\alpha$. In addition, sTNFR may also block TNF $\alpha$ binding to TNFR on neurons to further reduce neuronal activity and the interaction between neuron and glia (Fellin and Carmignoto, 2004; Haydon et al, 2009; Perea et al, 2009).

Target gene expression by HSV vector may depend on a few factors, for examples, backbone and promoter, and so on. Two distinct types of HSV-1-based vectors, recombinant (genomic) and amplicon, have been developed (Nunez et al, 2001). The recombinant non-replicating HSV vector used in this study was created by deletion of essential genes from HSV-1, a linear, double-stranded neurotrophic DNA virus (Fink et al, 1996). Amplicons, on the other hand, are bacterial plasmids that carry one or several transgenes, an origin of DNA replication, and a DNA cleavage/packaging signal. These vectors are replication defective and, therefore, depend on HSV-1 helper functions for replication and packaging into virions (Nunez et al, 2001). HSV-1 amplicon vector under the control of the IE4/5 promoter induces the number of GFP-fluorescent green monkey kidney cells reaching a peak at day 3 after infection and waning at day 5 in in vitro (Nunez et al, 2001). Similarly, in in vivo study, transgene expression of LacZ mediated by HSV-1 amplicon vector microinjected into the nucleus accumbens shell in rat is apparent within hours postinjection, reaches at peak by day 3, and largely dissipates by day 6 (Barrot et al, 2002). HSV-1 vectors encoding $I L-12$ and $I L-18$ genes with the IE4/5 promoter induced detectable expression of IL-12 or IL18 in serum 1-4 days, and the expression gradually decreased by day 7 (Ino et al, 2006). In this study, we used a non-replicating recombinant HSV with transgene expression under the control of the HSV IE ICP0 promoter, and found the expression of sTNFR or GFP 10 days after injection of the vector into the brain. Although we did not perform a formal evaluation of the full time course of expression, expression at 10 days is well within the window that we and others have observed using genomic HSV vectors, with viral IE promoters driving transgene expression. The enkephalin expressed by recombinant HSV with HCMV promoter lasted a few weeks (Antunes Bras et al, 1998; Lu et al, 2008; Wilson et al, 1999; Yeomans et al, 2004; Yeomans and Wilson, 2009).

Proinflammatory mediators can exert direct actions on neurons (Zhang et al, 2008) as well as induce various downstream changes that alter neuronal function, potentially contributing to opioid withdrawal (Nakagawa and Satoh, 2004). Chronic adaptive molecular mechanisms involve gene expression and/or some protein kinases, which are relevant for signaling processes involving protein phosphorylation and gene expression (Liu and Anand, 2001). Therefore, proteins including MAP kinases and transcriptional factors (Fos and CREB) were examined in this study.

ERK1/2 is a family of serine/threonine protein kinases that have been functionally linked to addiction through phosphorylation of transcription factors leading to changes in target gene expression (Liu and Anand, 2001). The drug-induced changes in gene expression are considered to be the main reason for the long-lasting alterations in brain neuronal plasticity responsible for the state of addiction (Nestler, 2004). Recently, several studies have shown that the spinal ERK pathway contributes to naloxone- precipitated withdrawal in morphine-dependent rats (Cao et al, 2005; Ren et al, 2004). Chronic morphine treatment increases ERK1/2 catalytic activity in a regionspecific manner (Muller and Unterwald, 2004; Nunez et al, 2008 ) in the rat brain, and a significant elevation of pERK1/ 2 levels has been observed in the NTS $60 \mathrm{~min}$ after opioid antagonist administration (Nunez et al, 2008). In this study, we showed that phosphorylation of ERK1/2 in the PAG was upregulated in the rats with morphine withdrawal. Fos protein, the product of Fos IE gene has been used as a marker for neuronal activation. Phosphorylation of ERK is one of the major pathways for the induction of Fos. Morphine withdrawal-induced increase in ERK activity has resulted in an enhancement in the Fos/pCREB (Nunez et al, 2008). A strong induction of Fos expression in the PAG is found after naloxone injection to morphine-dependent rats (Chieng et al, 1995). Naloxone-induced morphine withdrawal activates ERK1/2 and increases Fos expression in rat paraventricular nucleus and NTS- $\mathrm{A}_{2}$ neurons; activated ERK1/2 is colocalized with Fos in the nuclei (Nunez et al, 2008). We observed that morphine withdrawal-induced overexpression of Fos was colocalized with the phosphorylation of ERK in the vlPAG. The transcription factor CREB has been implicated in neural plasticity, including the changes that occur during stress and drug addiction (Lane-Ladd et al, 1997; Maldonado et al, 1996; Nestler, 2001). Chronic morphine increases level of CREB in the CNS (Shaw-Lutchman et al, 2002; Widnell et al, 1994). Precipitated morphine withdrawal has been shown to increase phosphorylation of CREB, including elevated Fos expression in rats in the hypothalamic paraventricular nucleus (Laorden et al, 2002). Chronic morphine dependence exerts long-lasting effects of morphine dependence on gene expression in different sites at the supraspinal level (Blendy and Maldonado, 1998; Nestler, 2005). We observed an increase in CREB in neurons of the PAG. Taken together, our findings suggest that morphine withdrawal might stimulate the activity of PCREB in the PAG.

Indirect evidence links TNFR activation in neurons with pERK1/2, pCREB, and Fos, but additional studies will be required to confirm a specific role of these mediators in morphine withdrawal. There is other evidence that TNF $\alpha$ increased in states of inflammation induces pERK phosphorylation in neurons (Xu et al, 2010), and that enhanced ERK signaling facilitates Fos expression in drug abuse (Ferguson et al, 2006). CREB can be activated by kinases, including ERK1/2 and PKC, which induce its transcriptional activity (Johannessen et al, 2004). Morphine withdrawalinduced increases in ERK activity result in an enhancement in the Fos/pCREB (Nunez et al, 2008). We found that TNF $\alpha$ induced phosphorylation of ERK1/2 and CREB, and expression of Fos in the PAG. It is possible, although not firmly proven by these experiments, that $\mathrm{TNF} \alpha$ acting through TNFR on neurons increases the activity of ERK1/2 to induce downstream transcriptional activity.

In summary, these findings suggest that neuroimmune activation in the PAG plays an important role in the biochemical and behavioral manifestations of naloxoneprecipitated withdrawal from chronic morphine. The study confirmed our hypothesis that morphine withdrawal induced glial activation in the PAG releasing the proinflammatory cytokine $\mathrm{TNF} \alpha$, and that the glial TNF $\alpha$ bonded 
with TNFR located on the neurons in the PAG to induce phosphorylation of ERK1/2 and CREB, and expression of neuronal activation marker, Fos. We recognize that it is a very complex undertaking to understand the interactions of various cytokines and other biomarkers seen in opioid withdrawal-associated PAG with behavioral responses. The analysis of multiple biomarkers provides information as to what potential mediators are altered in the PAG. These data lay the groundwork for future studies aimed at integrating the observed glial, proinflammatory, and neuronal changes of markers in the PAG. The study may provide a novel therapeutic approach to morphine physical withdrawal response.

\section{ACKNOWLEDGEMENTS}

This work was supported by grants from the NIH DA020078 (SH), DA026734 (SH), DA025527 (SH), and NS066792 (SH), Department of Veterans Affairs, and the NINDS NS038850 and NIDDK DK044935 (DJF and MM). We acknowledge the excellent technical assistance of Vikram Thakur and Angela Koelsch.

\section{DISCLOSURE}

The authors declare no conflict of interest. None of the authors have received compensation for professional services or anticipate receiving such compensation in the near future.

\section{REFERENCES}

Antunes Bras JM, Epstein AL, Bourgoin S, Hamon M, Cesselin F, Pohl M (1998). Herpes simplex virus 1-mediated transfer of preproenkephalin A in rat dorsal root ganglia. J Neurochem 70: 1299-1303.

Bains JS, Oliet SH (2007). Glia: they make your memories stick!. Trends Neurosci 30: 417-424.

Bandler R, Shipley MT (1994). Columnar organization in the midbrain periaqueductal gray: modules for emotional expression? Trends Neurosci 17: 379-389.

Barrot M, Olivier JD, Perrotti LI, DiLeone RJ, Berton O, Eisch AJ et al (2002). CREB activity in the nucleus accumbens shell controls gating of behavioral responses to emotional stimuli. Proc Natl Acad Sci USA 99: 11435-11440.

Blendy JA, Maldonado R (1998). Genetic analysis of drug addiction: the role of cAMP response element binding protein. J Mol Med 76: 104-110.

Bozarth MA (1994). Physical dependence produced by central morphine infusions: an anatomical mapping study. Neurosci Biobehav Rev 18: 373-383.

Cami J, Farre M (2003). Drug addiction. N Engl J Med 349: 975-986.

Cao JL, He JH, Ding HL, Zeng YM (2005). Activation of the spinal ERK signaling pathway contributes naloxone-precipitated withdrawal in morphine-dependent rats. Pain 118: 336-349.

Castilho VM, Borelli KG, Brandao ML, Nobre MJ (2008). Anxietylike symptoms induced by morphine withdrawal may be due to the sensitization of the dorsal periaqueductal grey. Physiol Behav 94: $552-562$.

Chieng B, Christie MD (1996). Local opioid withdrawal in rat single periaqueductal gray neurons in vitro. J Neurosci 16: 7128-7136.
Chieng B, Keay KA, Christie MJ (1995). Increased fos-like immunoreactivity in the periaqueductal gray of anaesthetised rats during opiate withdrawal. Neurosci Lett 183: 79-82.

Christie MJ, Williams JT, Osborne PB, Bellchambers CE (1997). Where is the locus in opioid withdrawal? Trends Pharmacol Sci 18: $134-140$

Couceyro P, Douglass J (1995). Precipitated morphine withdrawal stimulates multiple activator protein-1 signaling pathways in rat brain. Mol Pharmacol 47: 29-39.

Fellin T, Carmignoto G (2004). Neurone-to-astrocyte signalling in the brain represents a distinct multifunctional unit. J Physiol 559(Part 1): 3-15.

Ferguson SM, Fasano S, Yang P, Brambilla R, Robinson TE (2006). Knockout of ERK1 enhances cocaine-evoked immediate early gene expression and behavioral plasticity. Neuropsychopharmacology 31: 2660-2668.

Fink DJ, DeLuca NA, Goins WF, Glorioso JC (1996). Gene transfer to neurons using herpes simplex virus-based vectors. Annu Rev Neurosci 19: 265-287.

Fishbain DA, Rosomoff HL, Rosomoff RS (1992). Drug abuse, dependence, and addiction in chronic pain patients. Clin J Pain 8: 77-85.

Gellert VF, Holtzman SG (1978). Development and maintenance of morphine tolerance and dependence in the rat by scheduled access to morphine drinking solutions. J Pharmacol Exp Ther 205: 536-546.

Guo W, Wang H, Watanabe M, Shimizu K, Zou S, LaGraize SC et al (2007). Glial-cytokine-neuronal interactions underlying the mechanisms of persistent pain. J Neurosci 27: 6006-6018.

Halassa MM, Fellin T, Haydon PG (2007). The tripartite synapse: roles for gliotransmission in health and disease. Trends Mol Med 13: $54-63$.

Hao S, Hu J, Fink DJ (2009). Transgene-mediated enkephalin expression attenuates signs of naloxone-precipitated morphine withdrawal in rats with neuropathic pain. Behav Brain Res 197: 84-89.

Hao S, Mamiya K, Takahata O, Iwasaki H, Mata M, Fink DJ (2003a). Nifedipine potentiates the antinociceptive effect of endomorphin-1 microinjected into the periaqueductal gray in rats. Anesth Analg 96: 1065-1071; table of contents.

Hao S, Mata M, Glorioso JC, Fink DJ (2007). Gene transfer to interfere with TNFalpha signaling in neuropathic pain. Gene Ther 14: 1010-1016.

Hao S, Mata M, Wolfe D, Huang S, Glorioso JC, Fink DJ (2003b). HSV-mediated gene transfer of the glial cell-derived neurotrophic factor provides an antiallodynic effect on neuropathic pain. Mol Ther 8: 367-375.

Hao S, Mata M, Wolfe D, Huang S, Glorioso JC, Fink DJ (2005). Gene transfer of glutamic acid decarboxylase reduces neuropathic pain. Ann Neurol 57: 914-918.

Hao S, Takahata O, Mamiya K, Iwasaki H (2002). Sevoflurane suppresses noxious stimulus-evoked expression of Fos-like immunoreactivity in the rat spinal cord via activation of endogenous opioid systems. Life Sci 71: 571-580.

Harris GC, Aston-Jones G (1994). Involvement of D2 dopamine receptors in the nucleus accumbens in the opiate withdrawal syndrome. Nature 371: 155-157.

Haydon PG, Blendy J, Moss SJ, Rob Jackson F (2009). Astrocytic control of synaptic transmission and plasticity: a target for drugs of abuse? Neuropharmacology 56(Suppl 1): 83-90.

Hofford RS, Hodgson SR, Roberts KW, Bryant CD, Evans CJ, Eitan S (2009). Extracellular signal-regulated kinase activation in the amygdala mediates elevated plus maze behavior during opioid withdrawal. Behav Pharmacol 20: 576-583.

Hutchinson MR, Bland ST, Johnson KW, Rice KC, Maier SF, Watkins LR (2007). Opioid-induced glial activation: mechanisms of activation and implications for opioid analgesia, dependence, and reward. Scientific World J 7: 98-111. 
Hutchinson MR, Lewis SS, Coats BD, Skyba DA, Crysdale NY, Berkelhammer DL et al (2009). Reduction of opioid withdrawal and potentiation of acute opioid analgesia by systemic AV411 (ibudilast). Brain Behav Immun 23: 240-250.

Ino Y, Saeki Y, Fukuhara H, Todo T (2006). Triple combination of oncolytic herpes simplex virus-1 vectors armed with interleukin12 , interleukin-18, or soluble B7-1 results in enhanced antitumor efficacy. Clin Cancer Res 12: 643-652.

Johannessen M, Delghandi MP, Moens U (2004). What turns CREB on? Cell Signal 16: 1211-1227.

Johnston IN, Milligan ED, Wieseler-Frank J, Frank MG, Zapata V, Campisi J et al (2004). A role for proinflammatory cytokines and fractalkine in analgesia, tolerance, and subsequent pain facilitation induced by chronic intrathecal morphine. J Neurosci 24: 7353-7365.

Kirby KC, Stitzer ML, Heishman SJ (1990). Acute opioid physical dependence in humans: effect of varying the morphine-naloxone interval II. J Pharmacol Exp Ther 255: 730-737.

Koob GF, Le Moal M (1997). Drug abuse: hedonic homeostatic dysregulation. Science 278: 52-58.

Lane-Ladd SB, Pineda J, Boundy VA, Pfeuffer T, Krupinski J, Aghajanian GK et al (1997). CREB (cAMP response elementbinding protein) in the locus coeruleus: biochemical, physiological, and behavioral evidence for a role in opiate dependence. J Neurosci 17: 7890-7901.

Laorden ML, Nunez C, Almela P, Milanes MV (2002). Morphine withdrawal-induced $\mathrm{c}$-fos expression in the hypothalamic paraventricular nucleus is dependent on the activation of catecholaminergic neurones. J Neurochem 83: 132-140.

Laschka E, Teschemacher H, Mehraein P, Herz A (1976). Sites of action of morphine involved in the development of physical dependence in rats. II. Morphine withdrawal precipitated by application of morphine antagonists into restricted parts of the ventricular system and by microinjection into various brain areas. Psychopharmacologia 46: 141-147.

Ledeboer A, Hutchinson MR, Watkins LR, Johnson KW (2007a). Ibudilast (AV-411). A new class therapeutic candidate for neuropathic pain and opioid withdrawal syndromes. Expert Opin Invest Drugs 16: 935-950.

Ledeboer A, Liu T, Shumilla JA, Mahoney JH, Vijay S, Gross MI et al (2007b). The glial modulatory drug AV411 attenuates mechanical allodynia in rat models of neuropathic pain. Neuron Glia Biol 2: 279-291.

Lewis S, Hutchinson M, Coats B, Brzeski A, Maier S, Watkins L et al (2006). AV411, a blood-brain barrier permeable glial activation inhibitor, reduces morphine withdrawal behaviors in rats. Proc Soc Neurosci: 765: 762.

Liu JG, Anand KJ (2001). Protein kinases modulate the cellular adaptations associated with opioid tolerance and dependence. Brain Res Brain Res Rev 38: 1-19.

Lu Y, McNearney TA, Wilson SP, Yeomans DC, Westlund KN (2008). Joint capsule treatment with enkephalin-encoding HSV-1 recombinant vector reduces inflammatory damage and behavioural sequelae in rat CFA monoarthritis. Eur J Neurosci 27: 1153-1165.

Maldonado R, Blendy JA, Tzavara E, Gass P, Roques BP, Hanoune J et al (1996). Reduction of morphine abstinence in mice with a mutation in the gene encoding CREB. Science 273: 657-659.

Maldonado R, Stinus L, Gold LH, Koob GF (1992). Role of different brain structures in the expression of the physical morphine withdrawal syndrome. J Pharmacol Exp Ther 261: 669-677.

Mao J, Sung B, Ji RR, Lim G (2002). Chronic morphine induces downregulation of spinal glutamate transporters: implications in morphine tolerance and abnormal pain sensitivity. J Neurosci 22: 8312-8323.

Martin F, Laorden ML, Milanes MV (2009). Morphine withdrawal regulates phosphorylation of cAMP response element binding protein (CREB) through PKC in the nucleus tractus solitarius-A2 catecholaminergic neurons. J Neurochem 110: 1422-1432.

Mata M, Hao S, Fink DJ (2008). Gene therapy directed at the neuroimmune component of chronic pain with particular attention to the role of TNF alpha. Neurosci Lett 437: 209-213.

McPhie AA, Barr GA (2009). Regional Fos expression induced by morphine withdrawal in the 7-day-old rat. Dev Psychobiol 51: 544-552.

Muller DL, Unterwald EM (2004). In vivo regulation of extracellular signal-regulated protein kinase (ERK) and protein kinase B (Akt) phosphorylation by acute and chronic morphine. J Pharmacol Exp Ther 310: 774-782.

Nakagawa T, Satoh M (2004). Involvement of glial glutamate transporters in morphine dependence. Ann N Y Acad Sci 1025: 383-388.

Natsume A, Mata M, Goss J, Huang S, Wolfe D, Oligino T et al (2001). Bcl-2 and GDNF delivered by HSV-mediated gene transfer act additively to protect dopaminergic neurons from 6-OHDA-induced degeneration. Exp Neurol 169: 231-238.

Nestler EJ (2001). Molecular neurobiology of addiction. Am J Addict 10: 201-217.

Nestler EJ (2004). Molecular mechanisms of drug addiction. Neuropharmacology 47(Suppl 1): 24-32.

Nestler EJ (2005). Is there a common molecular pathway for addiction? Nat Neurosci 8: 1445-1449.

Nestler EJ, Aghajanian GK (1997). Molecular and cellular basis of addiction. Science 278: 58-63.

Nunez C, Castells MT, Laorden ML, Milanes MV (2008). Regulation of extracellular signal-regulated kinases (ERKs) by naloxone-induced morphine withdrawal in the brain stress system. Naunyn Schmiedebergs Arch Pharmacol 378: 407-420.

Nunez R, Ackermann M, Saeki Y, Chiocca A, Fraefel C (2001). Flow cytometric assessment of transduction efficiency and cytotoxicity of herpes simplex virus type 1-based amplicon vectors. Cytometry 44: 93-99.

Paxinos G, Watson C (1986). The Rat Brain in Stereotaxic Coordinates, 2nd edn. Academic Press: Sydney.

Peng XM, Zhou ZG, Glorioso JC, Fink DJ, Mata M (2006). Tumor necrosis factor-alpha contributes to below-level neuropathic pain after spinal cord injury. Ann Neurol 59: 843-851.

Perea G, Navarrete M, Araque A (2009). Tripartite synapses: astrocytes process and control synaptic information. Trends Neurosci 32: 421-431.

Pickering M, Cumiskey D, O'Connor JJ (2005). Actions of TNFalpha on glutamatergic synaptic transmission in the central nervous system. Exp Physiol 90: 663-670.

Raghavendra V, Rutkowski MD, DeLeo JA (2002). The role of spinal neuroimmune activation in morphine tolerance/hyperalgesia in neuropathic and sham-operated rats. J Neurosci 22: 9980-9989.

Raghavendra V, Tanga FY, DeLeo JA (2004). Attenuation of morphine tolerance, withdrawal-induced hyperalgesia, and associated spinal inflammatory immune responses by propentofylline in rats. Neuropsychopharmacology 29: 327-334.

Ren X, Noda Y, Mamiya T, Nagai T, Nabeshima T (2004). A neuroactive steroid, dehydroepiandrosterone sulfate, prevents the development of morphine dependence and tolerance via c-fos expression linked to the extracellular signal-regulated protein kinase. Behav Brain Res 152: 243-250.

Schafers M, Sommer C (2007). Anticytokine therapy in neuropathic pain management. Expert Rev Neurother 7: 1613-1627.

Shavit Y, Wolf G, Goshen I, Livshits D, Yirmiya R (2005). Interleukin-1 antagonizes morphine analgesia and underlies morphine tolerance. Pain 115: 50-59.

Shaw-Lutchman TZ, Barrot M, Wallace T, Gilden L, Zachariou V, Impey $S$ et al (2002). Regional and cellular mapping of cAMP response element-mediated transcription during naltrexoneprecipitated morphine withdrawal. J Neurosci 22: 3663-3672. 
Song P, Zhao ZQ (2001). The involvement of glial cells in the development of morphine tolerance. Neurosci Res 39: 281-286.

Stinus L, Le Moal M, Koob GF (1990). Nucleus accumbens and amygdala are possible substrates for the aversive stimulus effects of opiate withdrawal. Neuroscience 37: 767-773.

Stornetta RL, Norton FE, Guyenet PG (1993). Autonomic areas of rat brain exhibit increased Fos-like immunoreactivity during opiate withdrawal in rats. Brain Res 624: 19-28.

Taylor DA, Fleming WW (2001). Unifying perspectives of the mechanisms underlying the development of tolerance and physical dependence to opioids. J Pharmacol Exp Ther 297: 11-18.

Trang T, Sutak M, Quirion R, Jhamandas K (2003). Spinal administration of lipoxygenase inhibitors suppresses behavioural and neurochemical manifestations of naloxone-precipitated opioid withdrawal. Br J Pharmacol 140: 295-304.

Valjent E, Pages C, Herve D, Girault JA, Caboche J (2004). Addictive and non-addictive drugs induce distinct and specific patterns of ERK activation in mouse brain. Eur J Neurosci 19: $1826-1836$

Valverde O, Noble F, Beslot F, Dauge V, Fournie-Zaluski MC, Roques BP (2001). Delta9-tetrahydrocannabinol releases and facilitates the effects of endogenous enkephalins: reduction in morphine withdrawal syndrome without change in rewarding effect. Eur J Neurosci 13: 1816-1824.

Volterra A, Meldolesi J (2005). Astrocytes, from brain glue to communication elements: the revolution continues. Nat Rev Neurosci 6: 626-640.
Wei E, Loh H (1976). Physical dependence of opiate-like peptides. Science 193: 1262-1263.

Widnell KL, Russell DS, Nestler EJ (1994). Regulation of expression of cAMP response element-binding protein in the locus coeruleus in vivo and in a locus coeruleus-like cell line in vitro. Proc Natl Acad Sci USA 91: 10947-10951.

Williams JT, Christie MJ, Manzoni O (2001). Cellular and synaptic adaptations mediating opioid dependence. Physiol Rev 81: 299-343.

Wilson SP, Yeomans DC, Bender MA, Lu Y, Goins WF, Glorioso JC (1999). Antihyperalgesic effects of infection with a preproenkephalin-encoding herpes virus. Proc Natl Acad Sci USA 96: 3211-3216.

Xu ZZ, Zhang L, Liu T, Park JY, Berta T, Yang R (2010). et al. Resolvins RvE1 and RvD1 attenuate inflammatory pain via central and peripheral actions. Nat Med 16: 592-597; 591 following 597. .

Yeomans DC, Jones T, Laurito CE, Lu Y, Wilson SP (2004). Reversal of ongoing thermal hyperalgesia in mice by a recombinant herpesvirus that encodes human preproenkephalin. Mol Ther 9: 24-29.

Yeomans DC, Wilson SP (2009). Herpes virus-based recombinant herpes vectors: gene therapy for pain and molecular tool for pain science. Gene Ther 16: 502-508.

Zhang RX, Li A, Liu B, Wang L, Ren K, Zhang H et al (2008). IL-1ra alleviates inflammatory hyperalgesia through preventing phosphorylation of NMDA receptor NR-1 subunit in rats. Pain 135: 232-239. 